\title{
A follow-up analysis of positron emission tomography/ computed tomography in detecting hidden malignancies at the time of diagnosis of membranous nephropathy
}

\author{
Zhonglin Feng ${ }^{1}$, Shuxia Wang ${ }^{2}$, Yanlin Huang ${ }^{3}$, Xinling Liang ${ }^{1}$, Wei Shi ${ }^{1}$ and Bin \\ Zhang $^{1}$ \\ ${ }^{1}$ Department of Nephrology, Guangdong General Hospital, Guangdong Academy of Medical Sciences, Guangzhou, China \\ 2 Department of Nuclear Medicine and PET Center, Guangdong General Hospital, Guangdong Academy of Medical Sciences, \\ Guangzhou, China \\ ${ }^{3}$ Medical Genetics Center of Guangdong Women and Children Hospital, Guangzhou, China \\ Correspondence to: Bin Zhang, email: binzhang1970@yahoo.com \\ Wei Shi, email: 13925056339@139.com \\ Keywords: membranous nephropathy; malignancy; PET/CT, Pathology Section \\ Received: September 05, 2015 Accepted: February 05, $2016 \quad$ Published: February 19, 2016
}

\section{ABSTRACT}

\begin{abstract}
Membranous nephropathy (MN) is the most common kidney disease reported in a variety of malignant diseases. Search for an occult malignancy in MN has presented special challenges. $124 \mathrm{MN}$ patients with a physical examination not suspicious for cancer underwent screening for an occult malignancy with either 18F-Fluorodeoxyglucose positron emission tomography/computed tomography (FDG-PET/CT) scanning $(n=49)$ or conventional screening $(n=75)$ at the time of diagnosis of MN, and were followed up (median,28 months). 154 patients who refused to undergo any screening were followed up (median, 30 months). In FDGPET/CT cohort, $5(\mathbf{1 0 . 2 0 \% )}$ ) patients were screened and confirmed as malignancy, in contrast, $1(1.33 \%)$ patient in conventional screening cohort. During followup, none of malignancy was detected in FDG-PET/CT cohort, 3(4.05\%) patients in conventional screening cohort, and 8(5.19\%) patients in no-screening cohort. All 6 cases of cancer were detected at early stages and underwent curative resection, and after the resection, proteinuria decreased. In contrast, 11 cases of cancer detected during follow-up died without any remission of proteinuria. These preliminary data provide the first evidence for a potential cancer surveillance that the malignancy screening either through conventional or by PET-CT at the diagnosis of MN led to an early diagnosis and curative treatment.
\end{abstract}

\section{INTRODUCTION}

Membranous nephropathy (MN) is the most common kidney disease reported in a variety of malignant diseases. The list of malignancies occurring excessively in $\mathrm{MN}$ has expanded to include a much broader range of neoplasms, including carcinomas of lung, esophagus, colon, breast, stomach, prostate and lymphoma etc $[1,2]$. $\mathrm{MN}$ is the most common cause of nephrotic syndrome in adult. It is defined at the histopathologic level by the presence of immune complexes on the extracapillary side of the glomerular basement membrane. The exact etiology of $\mathrm{MN}$ is still unclear. Approximately $75 \%$ of the cases of $\mathrm{MN}$ are idiopathic, or primary, membranous nephropathy (IMN). The remainder is associated with a variety of conditions thought to secondarily cause $\mathrm{MN}$; these include systemic lupus erythematosus, hepatitis B antigenemia or other chronic infections, and, historically, a number of drugs and toxins such as therapeutic gold salts, D-penicillamine, and agents containing mercury [3].

The association between $\mathrm{MN}$ and malignancy was first reported in 1966, when Lee et al.[4] reported that $11 \%$ of patients with nephrotic syndrome had carcinoma. Since then, several case series suggested a link between $\mathrm{MN}$ and malignancy; although the true prevalence of malignancy in patients with $\mathrm{MN}$ remains unknown, it has been variously estimated as ranging between 5 and $22 \%$ [5-10]. In the largest such study, Lefaucheur et al.[10] 
reported a prevalence of malignancy of $10 \%$ in a review of 240 patients with biopsy-proven $\mathrm{MN}$, and this was about 10 -fold higher in patients with $\mathrm{MN}$ than in the general population. Recently, a meta-analysis of cohort studies in Caucasian population revealed a close association between $\mathrm{MN}$ and cancer with a prevalence rate of $10 \%$ and emphasized the importance of an extensive screening for malignancy in patients diagnosed with $\mathrm{MN}$ [11].

Search for an occult malignancy in patients with newly diagnosed $\mathrm{MN}$ has presented special challenges. The evidence review in the Kidney Disease: Improving Global Outcomes (KDIGO) Clinical Practice Guidelines (http://www.kdigo.org) has confirmed the paucity of data to support the recommendations for screening an occult malignancy in $\mathrm{MN}$, and further studies are needed to investigate the effectiveness of screening modality in this population [12]. In $\mathrm{MN}$, malignancies can occur in any anatomic site, making it difficult to identify practical, effective screening and prevention strategies [11]. On the other hand, of the patients with malignancy-associated MN, only $20 \pm 6.8 \%$ had the diagnosis of malignancy before the diagnosis of MN. For the remaining $80 \pm 15 \%$, the cancer was diagnosed at the time of or following the diagnosis of $\mathrm{MN}$ [11]. MN may be the first clinical manifestation of an occult malignancy, and patients suffering from $\mathrm{MN}$ develop diverse spectrum of new cancers during the following years [9-11]. Therefore, screening at the time of diagnosis of $\mathrm{MN}$ is worthwhile, as this may be the first sign of occult malignancy. Of these with malignancy-associated $\mathrm{MN}$, only a minority of patients were known to have symptoms related to their cancer at the time of kidney biopsy. In a majority of the cases, the malignancy was asymptomatic and only recognized by systematic diagnostic procedures triggered by the diagnosis of MN [10].

It is reasonable to perform routine screening for malignancy in patients with newly diagnosed MN once other secondary causes have been excluded. The conventional screening modality may include a complete physical examination, laboratory tests, gastrointestinal endoscopy, ultrasonography, $\mathrm{X}$ radiation study, tumor markers and gynecologic examination in women. However, data from these conventional screening modalities in $\mathrm{MN}$ is still unavailable. On the other hand, ${ }^{18} \mathrm{~F}$-Fluorodeoxyglucose positron emission tomography/ computed tomography (FDG-PET/CT) scanning can detect subclinical primary tumors as well as metastatic lesions in a wide range of malignancies [13]. FDG-PET/ $\mathrm{CT}$ is more accurate in detecting cancer and provides fewer equivocal findings than PET alone [14-17], CT alone, or separately acquired PET and CT studies in a head to head comparison [18]. For cancer staging, FDG-PET/ $\mathrm{CT}$ is also more accurate than either modality alone, as shown for lung cancer [19,20], colorectal cancer [17], and lymphoma [21].

In this study, we explored the use of FDG-PET/CT scanning for early detection in patients with a physical examination not suspicious for cancer at the time of diagnosis of $\mathrm{MN}$, and compare the effectiveness of FDG-PET/CT scanning with that of routine conventional screening.

\section{RESULTS}

Between November 2007 and April 2014, 305 consecutive patients were newly diagnosed with $\mathrm{MN}$ (Figure 1).Of these,124 presumed idiopathic MN patients

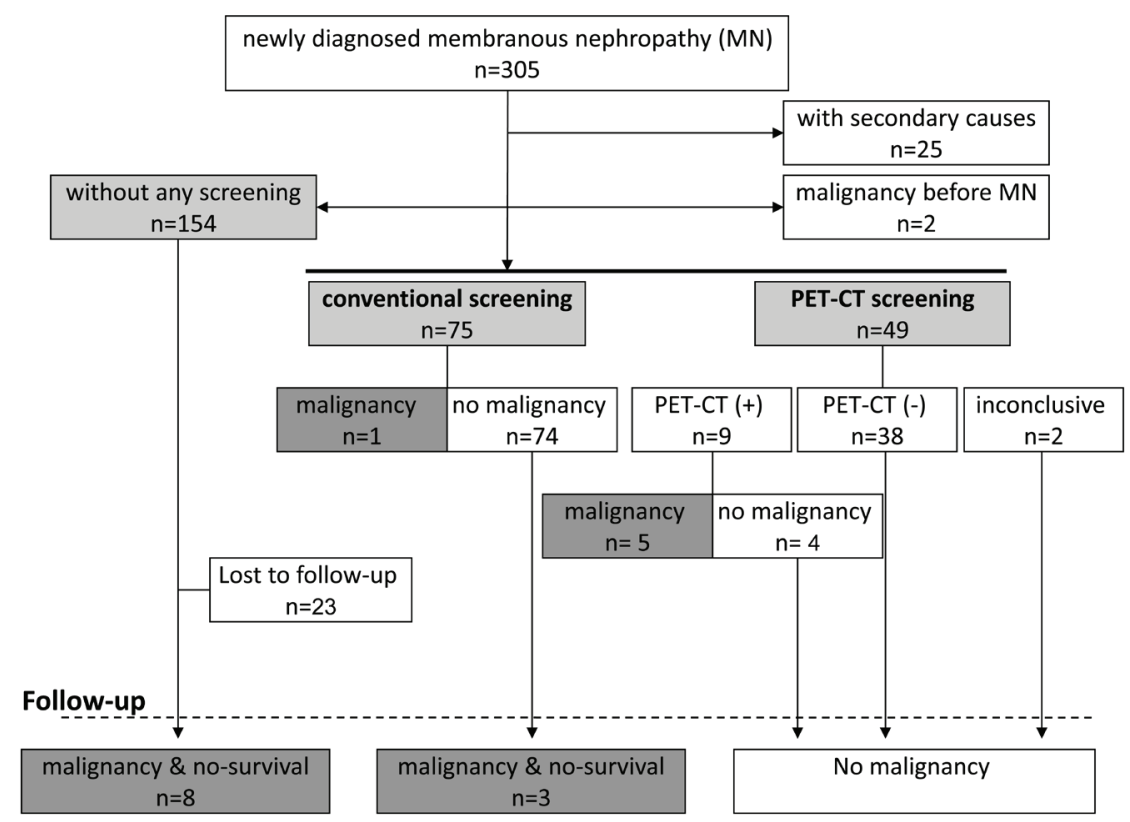

Figure 1: FDG-PET/CT and conventional malignancy screening. PET/CT ${ }^{18}$ F-Fluorodeoxyglucose positron emission tomography/computed tomography. 
Table 1: Characteristics of study cohorts

\begin{tabular}{|c|c|c|c|c|}
\hline & no screening & $\begin{array}{l}\text { conventional } \\
\text { screening }\end{array}$ & PET-CT screening & $p$ value \\
\hline & $n=154$ & $n=75$ & $n=49$ & \\
\hline age & $50(26.25)$ & $56(14.75)$ & $59.5(19.75)$ & 0.064 \\
\hline female sex, $\mathrm{n}(\%)$ & $91(59.1)$ & $40(53.33)$ & $24(48.98)$ & 0.410 \\
\hline proteinuria (g/24 h) & $2.92(3.44)$ & $3.57(4.51)$ & $4(5.42)$ & 0.089 \\
\hline eGFR (ml/min*1.73m2) & $89.4(42.99)$ & $73.45(46.53)$ & $72.53(56.16)$ & 0.643 \\
\hline smoking ,n (\%) & $11(7.14)$ & $5(6.67)$ & $4(8.16)$ & 0.951 \\
\hline alcohol abuse, n (\%) & $3(1.95)$ & $3(4)$ & $2(4.08)$ & 0.548 \\
\hline hypertension, n (\%) & $36(23.38)$ & $14(18.67)$ & $8(16.33)$ & 0.492 \\
\hline malignancy total ,n (\%) & $8(5.19)$ & $4(5.41)$ & $5(10.42)$ & 0.409 \\
\hline malignancy at kidney biopsy, n (\%) & --- & $1(1.33)$ & $5(10.20)$ & 0.035 \\
\hline malignancy during follow-up, n (\%) & $8(5.19)$ & $3(4.05)$ & 0 & 0.272 \\
\hline follow-up time, months & $30(36.98)$ & $29(34.75)$ & $27(15)$ & 0.582 \\
\hline lost to follow-up, n (\%) & $23(14.94)$ & $3(4)$ & $1(2.04)$ & 0.005 \\
\hline
\end{tabular}

Table 2: MN Patients with finally confirmed malignancies

\begin{tabular}{|c|c|c|c|c|c|c|c|c|c|}
\hline & $\begin{array}{l}\text { age/ } \\
\text { gender }\end{array}$ & screening & malignancy & $\begin{array}{l}\text { pathology } \\
\text { /stage }\end{array}$ & \begin{tabular}{|l} 
follow- \\
up \\
(mo)
\end{tabular} & survival & $\begin{array}{l}\text { surgical } \\
\text { resection }\end{array}$ & $\begin{array}{l}\text { proteinuria } \\
(\mathrm{g} / 24 \mathrm{~h})\end{array}$ & $\begin{array}{l}\text { proteinuria } \\
\text { after resection* }\end{array}$ \\
\hline 1 & $49 / \mathrm{M}$ & Conventional $(+)$ & colon & $\begin{array}{l}\text { adenocarcinoma } \\
\text { /T3N2M1 }\end{array}$ & 74 & yes & yes & 3.14 & disappearance \\
\hline 2 & 73/M & PET-CT $(+)$ & prostate & \begin{tabular}{|l|} 
adenocarcinoma \\
/Gleason score \\
$4+3$
\end{tabular} & 35 & yes & yes & 2.87 & reduction \\
\hline 3 & $65 / \mathrm{M}$ & PET-CT $(+)$ & lung & \begin{tabular}{|l|} 
adenocarcinoma \\
/ T1N0M0
\end{tabular} & 35 & yes & yes & 15.43 & reduction \\
\hline 4 & $50 / \mathrm{F}$ & PET-CT $(+)$ & thyroid & $\begin{array}{l}\text { adenocarcinoma } \\
\text { / T1N0M0 }\end{array}$ & 28 & yes & yes & 5.25 & reduction \\
\hline 5 & 78/M & PET-CT $(+)$ & lung & $\begin{array}{l}\text { adenocarcinoma } \\
\text { / T1N0M0 }\end{array}$ & 46 & yes & yes & 1.51 & disappearance \\
\hline 6 & $69 / \mathrm{M}$ & PET-CT $(+)$ & stomach & $\begin{array}{l}\text { adenocarcinoma } \\
\text { / T1N1M0 }\end{array}$ & 81 & yes & yes & 8.15 & disappearance \\
\hline 7 & $75 / \mathrm{F}$ & Conventional(-) & breast & N/A & 28 & no & no & 4.56 & no remission \\
\hline 8 & $54 / \mathrm{M}$ & Conventional(-) & colon & $\mathrm{N} / \mathrm{A}$ & 36 & no & no & 1.40 & no remission \\
\hline 9 & $74 / \mathrm{M}$ & Conventional(-) & lung & N/A & 51 & no & no & 3.59 & no remission \\
\hline 10 & $69 / \mathrm{F}$ & no & lung & N/A & 15 & no & no & 3.95 & no remission \\
\hline 11 & 66/M & no & stomach & $\mathrm{N} / \mathrm{A}$ & 19 & no & no & 4.46 & no remission \\
\hline 12 & $64 / F$ & no & lung & $\mathrm{N} / \mathrm{A}$ & 32 & no & no & 3.9 & no remission \\
\hline 13 & $31 / \mathrm{M}$ & no & lung & $\begin{array}{l}\text { adenocarcinoma } \\
\text { / T2N1M1 }\end{array}$ & 18 & no & yes & 1.62 & no remission \\
\hline 14 & 76/M & no & colon & $\mathrm{N} / \mathrm{A}$ & 73 & no & no & 2.88 & no remission \\
\hline 15 & $74 / \mathrm{F}$ & no & N/A & N/A & 77 & no & no & 2.14 & no remission \\
\hline 16 & $74 / \mathrm{M}$ & no & $\mathrm{N} / \mathrm{A}$ & $\mathrm{N} / \mathrm{A}$ & 58 & no & no & 7.4 & no remission \\
\hline 17 & $89 / \mathrm{M}$ & no & prostate & N/A & 58 & no & no & 1.84 & no remission \\
\hline
\end{tabular}

* Proteinuria after resection of malignancy: 1, disappearance: proteinuria $<0.15 \mathrm{~g} /$ day; 2 , reduction: proteinuria $<1 \mathrm{~g} / \mathrm{day}$.

with a physical examination not suspicious for cancer underwent screening for an occult malignancy with either FDGPET/CT scanning $(n=49)$ or the conventional screening $(n=75)$ (Figure 1$)$. Of these remaining 154 $\mathrm{MN}$ patients, they refused to received any screening. The baseline characteristics of 3 cohorts were similar (Table 1).

Of the 49 patients, FDGPET/CT scanning detected likely malignant lesions in 9 (18.37\%), among which
$5(10.20 \%)$ patients were subsequently confirmed as malignant (Figure 1). In contrast, of the 75 patients, the conventional screening detected malignant lesion in 1 $(1.33 \%)$.

Three $(4.05 \%)$ patients who were initially negative in the conventional screening were subsequently confirmed as malignant (Figure 1 and Tables 1 \& 2) during a median follow-up of 29 months (IQR, 34.75 months). In 
Table 3: Characteristics of MN patients with malignancy or without malignancy

\begin{tabular}{|l|l|l|l|l|}
\hline & malignancy & no-malignancy & $\boldsymbol{p}$ value & $\begin{array}{l}\text { Age-adjusted } \\
\boldsymbol{p} \text { value }\end{array}$ \\
\hline & $\boldsymbol{n}=\mathbf{1 7}$ & $\mathbf{n}=\mathbf{2 6 1}$ & & \\
\hline age & $69(15.5)$ & $52(25)$ & $<0.001$ & \\
\hline female sex, $\mathrm{( \% )}$ & $5(29.41)$ & $150(57.47)$ & 0.024 & \\
\hline proteinuria (g/24 h) & $3.59(2.92)$ & $3.28(4.38)$ & 0.637 & 0.785 \\
\hline eGFR (ml/min*1.73m2) & $55.06(58.87)$ & $83.18(52.81)$ & 0.009 & 0.592 \\
\hline smoking ,n (\%) & $1(5.88)$ & $19(7.28)$ & $>0.999$ & 0.421 \\
\hline alcohol abuse, $\mathrm{n}(\%)$ & 0 & $8(3.07)$ & $>0.999$ & 0.998 \\
\hline hypertension, $\mathrm{n}(\%)$ & $3(17.65)$ & $55(21.07)$ & 0.977 & 0.156 \\
\hline
\end{tabular}

contrast, during a median follow-up of 27 months (IQR, 15 months), none of the patients with initially negative FDGPET/CT was identified as being malignant. As a result, the sensitivity of FDG-PET/CT was $100 \%(5 / 5)$, while that of the extensive conventional screening was only $25 \%(1 / 4)$. In contrast, of these 154 patients who refused to received any screening, $8(5.19 \%)$ patients were subsequently confirmed as malignant (Figure 1 and Tables $1 \& 2$ ) during a median follow-up of 30 months (IQR, 36.98 months). Finally, a total of $5.41 \%$ patients were identified as having cancer in the conventional screening cohort, and $5.19 \%$ in the no-screening cohort, which were lower than $10.42 \%$ in the FDG-PET/CT scanning cohort (Figure 1 and Tables 1 \& 2).

Of the total 17 patients with confirmed malignancies in 3 cohorts, tumors were found to occur in diverse anatomic sites, including lung (6), colon (3), prostate (2), stomach (2), breast (1) and thyroid (1) (Table 2). Of these, six patients underwent either FDGPET/CT scanning $(n=$ $5)$ or the conventional screening $(n=1)$ at the time of diagnosis of MN. All these six patients were diagnosed with adenocarcinoma at early stages and underwent curative resection, and after surgical resection the amount of proteinuria decreased (Table 2). Unfortunately, 3 patients who were initially negative in the conventional screening cohort and 8 patients in the no-screening cohort developed a malignancy during the follow-up. All these 11 patients died either as a direct or indirect result of their tumor and had persistent proteinuria without any remission(Table 2). Patients with malignancy-associated MN were significantly older than patients without malignancies, and had lower female to male sex ratio and lower estimated glomerular filtration rate (Table 3). However, these differences were no longer significant after adjusting for age.

\section{DISCUSSION}

In clinical practice, search for an occult malignancy in patients with $\mathrm{MN}$ has presented special challenges because of the diverse spectrum of $\mathrm{MN}$-associated malignancies [1, 2]. The KDIGO Clinical Practice Guideline for Glomerulonephritis (http://www.kdigo. org) has confirmed the paucity of data for screening an underlying malignancy in this population. This followup analysis of cohort study showed that the malignancy screening either through conventional or by FDG-PET/ $\mathrm{CT}$ scanning at the time of MN diagnosis led to an early diagnosis of cancer and curative treatment. It may be helpful for the design of prospective randomized studies.

Our results showed that whole-body FDG-PET/CT scanning at the time of diagnosis of $\mathrm{MN}$ identified occult malignancies in $10.2 \%$ of patients, which is similar with the previous reports $[10,11]$. In contrast, the conventional screening detected malignant lesion only in $1.33 \%$. The FDG-PET/CT scanning is a non-invasive whole-body imaging technique routinely used for the diagnosis of malignancies with high sensitivity $[22,23]$.The sensitivity of FDG-PET/CT was $100 \%$, while that of the conventional screening was only $25 \%$. In earlier studies, the majority of $\mathrm{MN}$-associated malignancies were discovered at the time of or following the diagnosis of $\mathrm{MN}$ [11]. And in this study, of the total 17 patients with confirmed malignancies, tumors were found to occur in diverse anatomic sites, including lung (6), colon (3), prostate (2), stomach (2), breast (1) and thyroid (1). The result is in agreement with earlier series in which cancers in $\mathrm{MN}$ can occur in diverse anatomic sites, [7-9,24,25], making it difficult to identify practical, effective screening and prevention strategies. Although the rate of detection of cancer on conventional screening remained lower compared to the FDG-PET/CT scanning, the search of a hidden malignancy either through conventional or by FDG-PET/CT scanning at the time of $\mathrm{MN}$ diagnosis appears as an attractive strategy since early diagnosis could imply better outcomes[9-11]. In this study, all these 6 patients who underwent screening and finally confirmed as having cancer (FDG-PET/CT scanning, $n=$ 5 or the conventional screening, $n=1$ ) were showed to be at early stages and underwent curative resection, and after surgical resection, the amount of proteinuria decreased. However, 3 patients who were initially negative in the conventional screening cohort and 8 patients in the noscreening cohort developed a malignancy, and died either as a direct or indirect result of their tumor and had persistent proteinuria without any remission.

Our study has several limitations. First, this is a 
retrospective cohort study and there is no independent validation cohort, although it is the first large study assessing FDG-PET/CT for the screening of hidden cancer in patients with MN. Nevertheless, it may be useful for the design of new prospective randomized studies comparing conventional screening strategy with FDG-PET/CT screening, also focusing on impact on survival. Second, a drawback of the application of FDG-PET/CT for the search of a hidden malignancy is the high percentage of false-positive findings, leading to unnecessary additional explorations. According to our results, the positive predictive value (PPV) of FDG-PET/CT was only 55.6\% (5/9). Considering the high cost of PET-CT, relatively low PPV for malignancy in MN, routine PET-CT screening in $\mathrm{MN}$ patients would be difficulty in current clinical practice. Thus stratify the MN patients for screening is particularly important. It is reported that anti-PLA2R is in an association with malignancy occurrence, and the status of anti-PLA2R may help stratify the MN patients for screening and justify the use of PET-CT screening $[26,27]$. Third, as FDG-PET/CT is not widely available and interpretation depends heavily on expertise, the implementation of this screening strategy may be difficult.

\section{MATERIALS AND METHODS}

\section{Patients}

A total of 305 consecutive patients with biopsy proven MN between November 2007 and April 2014 were identified (Figure 1). The kidney biopsies were performed at Guangdong General Hospital, South China University of Technology (SCUT). Diagnostic features of MN included capillary wall thickening, normal cellularity, IgG and $\mathrm{C} 3$ along capillary walls on immunofluorescence, and subepithelial deposits on electron microscopy. Of these, 25 patients who had secondary causes were excluded by using history, physical exam, and appropriate laboratory tests (Figure 1). Two patients who had malignancies before the diagnosis of $\mathrm{MN}$ were also excluded. 154 patients refused to undergo any malignancy screening at the time of kidney biopsy. In the end, 124 patients with presumed idiopathic MN signed a fully informed consent to undergo the conventional screening $(n=75)$ or FDGPET/CT scanning $(n=49)$ to investigate the presence of an occult malignancy at time of $\mathrm{MN}$ diagnosis (Figure 1).

This is a retrospective cohort study. The cohort of the conventional screening $(n=75)$ served as the control cohort and were not randomly assigned. But as shown in Table 1, baseline characteristics of both cohorts are comparable. The study protocol and data handling procedure approved by the Ethics Committee of Guangdong General Hospital.

\section{Conventional screening versus FDG-PET/CT scanning}

The spectrum of MN-associated cancers was diverse and the majority of tumor-associated MN patients had no cancer-related to symptoms at kidney biopsy $[1,2]$. Considering these concerns, we presumed that the wholebody PET-CT could be more suitable to detect such a broad spectrum of hidden cancers than the conventional screening, even if the conventional malignancy screening were extensive.

Conventional malignancy screening in this study included a complete physical examination, laboratory tests (complete blood count, fecal occult blood testing and serum chemistry panel), upper gastrointestinal endoscopy, colonoscopy, ultrasonography of thyroid gland and abdominal organs, or thoracoabdominal $\mathrm{X}$ radiation, tumor markers (CA125, CA199, carcinoembryonic antigen, prostate-specific antigen), and gynecologic examination in women, including ultrasonography.

FDG-PET/CT scanning was performed using an integrated whole body FDG-PET/CT scanner (Biograph Duo LSO, Siemens). ${ }^{18}$ F-FDG was synthesized with an automatic chemical module and an on-site cyclotron (RDS111, CTI Inc., Chicago, Illinois, USA). Radiochemical purity was greater than $95 \%$. Patients were fasted for at least $4 \mathrm{hr}$ before injection, serum glucose was $\leq 150 \mathrm{mg} / \mathrm{dL}$. $5.92 \mathrm{MBq} / \mathrm{kg}{ }^{18} \mathrm{~F}-\mathrm{FDG}$ was administered intravenously through iv canular, and uptake time was $60 \mathrm{~min}+10 \mathrm{~min}$, 3D requisition, $2 \mathrm{~min} / \mathrm{bed}$, iterative reconstruction (iteration 4 , subsets 8 ). CT part of $\mathrm{PET} /$ CT was performed without breath hold $(120 \mathrm{kVp}, 50$ $\mathrm{mAs})$. Two double certified physicians closely monitored patients on-site, one is a nuclear medicine physician and the other is a radiologist. Image report was written by the two physicians, combining PET and CT characteristics with consensus. In case of abnormal or suspicious findings, the patient was informed and appropriate diagnostic procedures to confirm or rule out malignancy were programmed, including biopsy, resection, or follow up. The follow up was made by telephone interview in a blinded manner.

\section{Statistical analysis}

Qualitative data was expressed as percentages, and quantitative data was presented as median and 25-75\% interquartile range or mean and standard deviation. The Fisher exact, Pearson chi-square test, continuity correction chi-square test or chi-square test were used to assess the relationships. The Mann-Whitney U or T test were used to assess the relationships between quantitative variables. Statistical significance was set at P less than 0.05, and all analyses were performed with the Statistical Package for the Social Sciences version 15.0 (SPSS Inc, Chicago, Ill). 


\section{ACKNOWLEDGMENTS}

We thank the staffs at the general database of GGH, Guangzhou, China. And, this work was supported by the Grant of China National Natural Science Foundation (81570642;81370808; 81270784) and the National Construction Projects for Key Clinical Specialties.

\section{CONFLICTS OF INTEREST}

None declared

\section{FUNDING}

The grant of China National Natural Science Foundation $(81570642 ; 81370808 ; 81270784)$; and the National Construction Projects for Key Clinical Specialties

\section{REFERENCES}

1. Cambier JF, Ronco P. Onco-nephrology: glomerular diseases with cancer. Clin J Am Soc Nephrol. 2012 ; $7: 1701-12$

2. Bacchetta J, Juillard L, Cochat P, Droz JP. Paraneoplastic glomerular diseases and malignancies. Crit Rev Oncol Hematol. 2009; 70:39-58.

3. Beck LH Jr. Membranous nephropathy and malignancy. Semin Nephrol. 2010 ;30:635-44.

4. Lee JC, Yamauchi H, Hopper J Jr. The association of cancer and the nephritic syndrome. Ann Intern Med. 1966; 64:4151.

5. Bjørneklett R, Vikse BE, Svarstad E, Aasarød K, Bostad L, Langmark F, Iversen BM. Long-term risk of cancer in membranous nephropathy patients. Am J Kidney Dis. 2007; 50:396-403.

6. Rihova Z, Honsova E, Merta M, Jancova E, Rysava R, Reiterova J, Zabka J, Tesar V. Secondary membranous nephropathy--one center experience. Ren Fail. 2005; 27:397-402.

7. Row PG, Cameron JS, Turner DR, Evans DJ, White RH, Ogg CS, Chantler C, Brown CB. Membranous nephropathy. Long-term follow-up and association with neoplasia. Q J Med. 1975; 44:207-39.

8. Cahen R, Francois B, Trolliet P, Gilly J, Parchoux B. Aetiology of membranous glomerulonephritis: a prospective study of 82 adult patients. Nephrol Dial Transplant. 1989; 4:172-80

9. Burstein DM, Korbet SM, Schwartz MM. Membranous glomerulonephritis and malignancy. Am J Kidney Dis. 1993; 22:5-10.

10. Lefaucheur C, Stengel B, Nochy D, Martel P, Hill GS, Jacquot C, Rossert J; GN-PROGRESS Study Group. Membranous nephropathy and cancer: Epidemiologic evidence and determinants of high-risk cancer association.
Kidney Int. 2006; 70:1510-7.

11. Leeaphorn N, Kue-A-Pai P, Thamcharoen N, Ungprasert P, Stokes MB, Knight EL. Prevalence of cancer in membranous nephropathy: a systematic review and metaanalysis of observational studies. Am J Nephrol. 2014; 40:29-35

12. Jhaveri KD, Shah $\mathrm{HH}$, Calderon $\mathrm{K}$, Campenot ES, Radhakrishnan J. Glomerular diseases seen with cancer and chemotherapy: a narrative review. Kidney Int. 2013; 84:3444.

13. Al-Sugair A, Coleman RE. Applications of PET in lung cancer. Semin Nucl Med. 1998; 28:303-19.

14. Schöder H, Yeung HW, Gonen M, Kraus D, Larson SM. Head and neck cancer: clinical usefulness and accuracy of PET/CT image fusion. Radiology. 2004; 231:65-72.

15. Bar-Shalom R, Yefremov N, Guralnik L, Gaitini D, Frenkel A, Kuten A, Altman H, Keidar Z, Israel O. Clinical performance of PET/CT in evaluation of cancer:additional value for diagnostic imaging and patient management. J Nucl Med. 2003 ;44:1200-9.

16. Yeung HW, Schöder H, Smith A, Gonen M, Larson SM. Clinical value of combined positron emission tomography/ computed tomography imaging in the interpretation of 2-deoxy-2-[F-18]fluoro-D-glucose- positron emission tomography studies in cancer patients. Mol Imaging Biol. $2005 ; 7: 229-35$.

17. Cohade C, Osman M, Leal J, Wahl RL. Direct comparison of (18)F-FDG PET and PET/CT in patients with colorectal carcinoma. J Nucl Med. 2003;44:1797-803.

18. Kim JH, Czernin J, Allen-Auerbach MS, Halpern BS, Fueger BJ, Hecht JR, Ratib O, Phelps ME, Weber WA. Comparison between 18F-FDG PET, in-line PET/CT, and software fusion for restaging of recurrent colorectal cancer. J Nucl Med. 2005;46:587-95.

19. Antoch G, Stattaus J, Nemat AT, Marnitz S, Beyer T, Kuehl H, Bockisch A, Debatin JF, Freudenberg LS. Non-small cell lung cancer: dual-modality PET/CT in preoperative staging. Radiology. 2003 ;229(2):526-33.

20. Lardinois D, Weder W, Hany TF, Kamel EM, Korom S, Seifert B, von Schulthess GK, Steinert HC. Staging of nonsmall-cell lung cancer with integrated positron-emission tomography and computed tomography. N Engl J Med. 2003; 348:2500-7.

21. Tatsumi M, Cohade C, Nakamoto Y, Fishman EK, Wahl RL. Direct comparison of FDG PET and CT findings in patients with lymphoma: initial experience. Radiology. 2005; 237:1038-45.

22. Kubota K. From tumor biology to clinical Pet: a review of positron emission tomography (PET) in oncology. Ann Nucl Med 2001;15:471-86.

23. Delgado-Bolton RC, Fernández-Pérez C, González-Maté A, Carreras JL.Meta-analysis of the performance of 18F-FDG PET in primary tumor detection in unknown primary tumors. J Nucl Med. 2003 ;44(8):1301-14. 
24. Hopper Jr J. Tumor-related renal lesions. Ann Intern Med 1974; 81: 550-551.

25. Zech P, Colon S, Pointet P, Deteix P, Labeeuw M, Leitienne $\mathrm{P}$. The nephrotic syndrome in adults aged over 60: etiology, evolution and treatment of 76 cases. Clin Nephrol 1982; 17: 232-236.

26. Qin W, Beck LH Jr, Zeng C, Chen Z, Li S, Zuo K, Salant DJ, Liu Z.Anti-phospholipase A2 receptor antibody in membranous nephropathy. J Am Soc Nephrol. 2011; 22:1137-43.

27. Debiec H, Ronco P. PLA2R autoantibodies and PLA2R glomerular deposits in membranous nephropathy. N Engl J Med. 2011;364:689-90. 